\title{
Lá traducción en la didática de las lenguas extranjeras
}

\author{
Giuseppa Giangrande ${ }^{l}$ \\ Carmen C. Castro Moreno \\ Rosa-Isabel Martínez Lillo \\ Violeta de la Jara Berenjeno
}

\begin{abstract}
The purpose of this article is to try to demonstrate the role of translation in the teaching and learning processes of foreign languages, with particular reference to the importance attributed to that skill/technique by different orientations/different approaches and didactic methods. We also intend to highlight the modalities of translation related, in particular, to the Italian, German, Arabic and Spanish languages, four different languages, although they are unified in the procedures we wish to emphasize: progression of teaching, textual typologies or their evaluation. In addition, we propose to argue the processes of lexicalization of neologisms or why the so-called Knowledge Metaphors guarantee the progression of statements, particularly in the case of literary texts, although they are also useful for other possibilities of translation that encompass Interpretive Learning.
\end{abstract}

Keywords: Didactics; Cognition; adaptation; translation-translation; interpretation; metaphors of knowledge; neologisms.

Resumen: El propósito del presente artículo es intentar demostrar la función de la traducción en los procesos de enseñanza y aprendizaje de las lenguas extranjeras, con especial referencia a la importancia atribuida a esa habilidad/técnica por las diferentes orientaciones/los diferentes enfoques y métodos didácticos. Se intentan destacar también las modalidades de traducción relacionadas, en particular, con la lengua italiana, alemana, árabe y española, cuatro idiomas diversos aunque unificables en los procedimientos que pretendemos destacar: la progresión de la enseñanza, las tipologías textuales o su evaluación. Adicionalmente nos proponemos argumentar los procesos de lexicalización de neologismos o por qué las denominadas Metáforas del Conocimiento garantizan la progresión de los enunciados, particularmente en el caso de textos literarios, aunque también sean útiles para otras posibilidades de traslación que engloben el Aprendizaje Interpretativo.

Palabras clave: Adaptación; traducción-traslación; interpretación; metáforas del conocimiento; neologismos.

1 Grupo de investigación HUM-978 liLETRAd: Dra. Giuseppa Giangrande, Direzione Didattica "Novelli"Monreale (Palermo); Dra. Carmen C. Castro Moreno, Universidad de Sevilla; Dra. Rosa-Isabel Martínez Lillo, Universidad Autónoma de Madrid; Dra. Violeta de la Jara Berenjeno, Universidad de Cádiz. 


\section{La didáctica de la traducción: italiano}

Giuseppa Giangrande

\subsection{Introducción}

La traducción forma parte del grupo de las habilidades integradas, especialmente de las habilidades relacionadas con la transformación de los textos, representa una de las habilidades que "superan" la subdivisión tradiciónal de las habilidades lingüisticas, referidas sobre todo a la recepción y a la producción. Esas habilidades (lingüísticas) se refieren también a y están relacionadas con otras habilidades, es decir las de transformación de los textos, entre ellas el dictado, la paráfrasis y la traducción (BALBONI, 2013). A diferencia de las habilidades lingüísticas primarias/fundamentales, la transformación de los textos supone y requiere una actividad más compleja, especialmente en el paso/ cambio oral-oral, un ejemplo del cual es la traducción simultánea (BALBONI, 2013).

En glotodidáctica la traducción se refiere a la producción de un texto escrito o oral "equivalente", por ejemplo en italiano, a un texto "original" en otro idioma, por el uso de diccionarios u otros materiales (BALBONI, 2015).

La traducción es también una técnica glotodidáctica, ya que representa una actividad útil para la adquisición/el aprendizaje de un idioma (BALBONI, 2013), pero al mismo tiempo debe ser considerada un "objetivo" de la actividad glotodidáctica y cuya utilidad/ ventaja está en identificar que no es posible traducir un texto "palabra por palabra" (BALBONI, 2015). Otra potencialidad de la traducción es la de "...funcionar/ obrar al mismo tiempo con la lengua extranjera y el italiano, pero también con las dos culturas y enciclopedias de referencia..." (BALBONI, 2015: 191).

\subsection{La traducción: utilización, potencialidad y límites}

La traducción, desde hace tiempo, y en particular con referencia a la orientación de tipo formalistico y del método de gramática-traducción, es fundamental en los procesos de enseñanza y aprendizaje de las lenguas extranjeras; en ese caso, la lengua es sobre todo un sistema de normas y listas lexicales.

Hoy en día ese tipo de orientación se encuentra especialmente en la enseñanza y aprendizaje del italiano L1(lengua nativa) y respecto a las lenguas extranjeras, es utilizada en las escuelas y universidades; con referencia a las lenguas clásicas (lengua latina y griega), siempre ha sido fundamental. En la orientación y los métodos de tipo comunicativo, la traducción por lo contrario, constituye una técnica que se debe "prescribir", ya que no es considerada como fructífera y eficaz (BALBONI, 2013).

Entre los "límites" de la traducción se encuentran (CARRERES, 2006; BALBONI, 2013):

- Es considerada artificial e ineficaz en los métodos de tipo comunicativo y queda circunscrita sólo a la lectura y a la escritura;

- La producción lingüística en lengua extranjera "muestra" las interferencias de la L1(lengua nativa);

- $\quad$ Es desmotivante, ya que es considerada un ejercicio de evaluación de los errores y no descuida las situaciones reales de comunicación;

- Es un proceso lento y complicado, debido al tiempo necesario para realizar ese tipo de actividad. 
Algunos investigadores (CARRERES, 2006) destacan también que, probablemente, no obstante el "rechazo" de la traducción como técnica eficaz para el aprendizaje de las lenguas extranjeras, esa nunca ha sido descartada en el "desarrollo" de los procesos de enseñanza y aprendizaje y recientemente ha sido revalorizada ya que, no obstante sus límites, en glotodidáctica se intenta demostrar que la traducción puede ser un instrumento/ recurso didáctico muy válido en la enseñanza de una lengua extranjera.

Entonces, ¿cuáles pueden ser los objetivos y las ventajas del uso de la traducción "pedagógica"? Balboni (2013) perfila:

- $\quad$ Ayuda en el proceso de la reflexión y conduce a la producción de metacompetencia;

- $\quad$ Es una herramienta útil para aprender;

- Desde el punto de vista de la psicolingüística la traducción desarrolla y profundiza los procesos controlados, que exigen atención y activan la memoria de corto plazo;

- Su finalidad principal es la análisis de los textos;

- Es importante para la reflexión intercultural.

Ha sido evidenciado que entre los límites de la traducción existe la demotivación, ya que esa actividad puede presentar dificultades; pero es posible convertirla en una actividad caracterizada por motivación, si se tienen en consideración algunos "aspectos" importantes (BALBONI, 2013), como:

- La selección de los textos, que desde una óptica de tipo psicologíco, tienen que ser relevantes;

- $\quad$ La traducción debe ser considerada una tarea factible y realizable;

- El trabajo de traducción, desde un punto de vista lingüístico, y la reflexión sobre el texto que hay que traducir tienen que conducir al placer de la traducción, y eso es realizable por actividades traslaticias basadas en la cooperación.

\subsection{Las modalidades de la traducción}

Desde hace tiempo la traducción es considerada una de las habilidades que tienen que ser desarrolladas y profundizadas en situaciones de aprendizaje de las lenguas extranjeras con alumnos con competencias lingüísticas de nivel intermedio alto o avanzado (TITONE, 1998).

Las diferentes modalidades desde las cuales una traducción puede ser realizada, con referencia especial a la lengua italiana, son así enumeradas (BALBONI, 2013):

- Traducción escrita lengua extranjera/ clásica- italiano: posibilita y favorece la educación lingüística, ya que tiene efecto en las lenguas, culturas y "enciclopedias"; esa modalidad de traducción es un recurso para activar los mecanismos productivos en las áreas de gramática del léxico y de la sintaxis del periodo, con referencia especial a la transformación de la estructura paratáctica en hipotáctica, que es típica de las lenguas románicas;

- Traducción oral de textos escritos lengua extranjera/ clásica- italiano: exige mucha concentración, pero puede resultar en una actividad motivante si es realizada en tiempos breves y utilizando la técnica de la grabación; 


\section{Conexão Letras}

- Traducción italiano- lengua extranjera/ clásica: ha sido rechazada y eliminada ya que es típica de la orientación de tipo formalistico y del método de gramáticatraducción, es muy difícil sobre todo desde el punto de vista morfosintáctico y porque es necesario el uso del diccionario;

- La traducción inversa/ retrotraducción: es la traducción de un texto traducido hacia la lengua del texto original, se hace sin referencias del texto original. La comparación de una retrotraducción con el texto original en ocasiones se utiliza como comprobación fiable para la traducción original. Ese tipo de traducción representa un desafio con el texto;

- Traducción de textos en lengua extranjera hacia otra lengua extranjera: puede ser utilizada en las escuelas donde se realiza el aprendizaje de diferentes idiomas; es una actividad motivante y en ese caso hay producción lingüística;

- Traducción diacrónica: su finalidad principal es activar la reflexión sobre el "cambio" de las variedades lingüísticas a través del tiempo.

Importante para la traducción en la didáctica de las lenguas extranjeras es la utilización de las nuevas tecnologías que convierten la traducción en una actividad/técnica motivante; modalidades de traducción relacionadas con las nuevas tecnologías pueden ser (BALBONI, 2013):

- Traducción de diálogos de películas extranjeras, a través de la visión de breves escenas con subtítulos en lengua original, para la comparación con el cine doblaje en italiano;

- Traducción de textos de canciones extranjeras: puede ser una actividad muy motivante si realizada a través del trabajo en grupo y también como actividad extraescolar;

- Traducción de textos de publicidad televisiva, que es una actividad útil y motivante, ya que - aunque difícil - muestra muchos elementos culturales.

\section{La didáctica de la traducción: alemán}

\section{Carmen C. Castro Moreno}

\subsection{Introducción}

Cuando nos enfrentamos al caso concreto de la lengua alemana y, en particular, a la didáctica de su traduccción, debemos considerar que el reto no es muy diferente al que pueda emplearse en el caso de otras lenguas extranjeras (Vid. ZARO, 1999, p. 531-555). No obstante, conviene matizar los siguientes aspectos, recomendables si queremos aplicarlos a la ciencia del futuro traductor o del profesor ya formado, pues la esencia teórica siempre es precisa mientras que el aspecto evolutivo se va modificando y coincide con la formación continua del profesional, indistintamente de cuál sea su área, campo o tema de estudio (Cfr. VERMEIREN, 2000, p. 355-370).

\subsection{Acciones genéricas}

Para aclarar en profundidad dichos aspectos, se hace necesario mencionar algunas acciones [Ac.] aplicables a las lenguas extranjeras que fueren de nuestro interés, referidos 
en ocasiones por diversos autores, entre los que destacan María José Viqueira (1992, p 76-78) y J. García Medall (2001, p. 113-136). Ofrecemos a continuación una síntesis:

$1^{\mathrm{a}}$-Ac. Acotar los ámbitos de la (inter)textualidad desde un punto de vista sintáctico y morfológico que nos facilite el intercambio de las ideas que se expresan en un texto o en un discurso determinado, pudiendo ser el canon establecido tanto a partir de una situación cotidiana como específica y de finalidad pragmática (textos jurídicos, científico-técnicos, sanitarios, etc.) Nos serviremos aquí de las características propias del Análisis del Discurso y de la Lingüística Textual. ${ }^{2}$

$2^{\mathrm{a}}$-Ac. Emplear un corpus aplicado al efecto de la traducción o interpretación a realizarse. Las nuevas bases de datos y programas específicos permiten delimitar de manera sencilla y rápida términos, aparte de poderse acceder a realizar búsquedas relacionadas y comparar fuentes. A este objeto siempre han existido agrupaciones de palabras o conjunto de temas históricos. ${ }^{3}$

$3^{\mathrm{a}}$-Ac. Recurrir a la psicolingüística y las gramáticas generativo-transformacional o funcional. El objetivo es enriquecer la práctica traslatoria a través del esclarecimiento de sus tipologías o pensamientos, desde los relacionados con el sistema de "oposiciones" o los que directamente implican a las estructuras profunda o superficial del lenguaje, donde se generan los pensamientos e ideas que se realizan en el habla.

$4^{\mathrm{a}}$-Ac. Atender a las interferencias, producidas en gran medida por los conocimientos que ya poseemos de otras lenguas más o menos dominadas, a veces porque nuestro inconsciente nos traiciona y termina traduciendo lo que no se pretende. Esa zona de nadie, la llamada "Interlengua", que parece no existir y ser artificial, es altamente dañina cuando se convierte en la sustitiva a los lenguajes naturales.

$5^{a}$-Ac. Cuidar el plano cognitivo, en dos vertientes: la neurológica (v1) y la perceptiva (v2). En un primer cercamiento a v1 afirmamos que son los factores ambientales los que determinarán que haya que modificar los parámetros traductológicos y adaptarlos a situaciones - indicios - que puedan acontecer, con un margen de error absoluto de $0 \%$ al $100 \%$. La neurología no es una ciencia certera que se haya podido descifrar mediante la constatación de datos, por lo que ha de apoyarse en el contraste o la mera hipótesis. En el caso de v2 podemos afirmar que la observación de las gesticulaciones y el lenguaje no oral a través de signos, señales o imágenes determina el sentido de los enunciados o actos de habla. ${ }^{4}$

6 -Ac. Emplear las Nuevas Tecnologías, innovando métodos relacionados con la Traducción e Interpretación, colaborando con científicos de ramas ajenas a la

2 Nos consta que estos aspectos que aquí se mencionan sirvirían de base para actualizar las Tesis más futuristas al respecto. La coherencia, el contexto, la cohesión... forman parte de un cúmulo de configuraciones metodológicas imposibles de ser obviadas.

3 Citar una fuente concreta sería posible, aunque no fiable. Dependiendo de la temática a la que nos enfrentáramos deberíamos ponderar cuáles son los mejores recursos o los óptimos.

4 Las teorías del sueño, de la hipnosis o del subconsciente. 
nuestra, que aporten conocimientos trasversales y complementarios. La voluntad de aprendizaje así como las cuestiones referidas a la ética medioambiental y al aprovechamiento de recursos y medios técnicos, son fundamentales.

\subsection{Implicativos de las denominadas Metáforas del Conocimiento (MC)}

Las Metáforas del Conocimiento están constituidas por los elementos discursivos, objetos, ideas, situaciones y acontecimientos, y personas o personajes que desencadenan que los hechos transcurran de un modo concreto y no de otro y se dirijan a su finalidad inmediata. ${ }^{5} \mathrm{Su}$ "misión" es facilitar la descripción, explicación y predicción. Y será el conjunto de tales componentes los que precisamente simplifiquen la traducción o interpretación. Curiosamente el autor de las palabras no es siempre consciente de producirlas, son en su mayoría "causalidades", que se transforman en símbolos del pensamiento de quien las produce o son el producto de la imaginación. Generalmente nos ayudan a determinar personalidades, intereses e incluso a controlar los fenómenos.

Por poner un ejemplo clarificador, podríamos ponernos en el papel de lectores de un libro. Al finalizarlo, estableceremos conclusiones concretas: el protagonista de la historia se encuentra con una persona $x$, que le acerca a un lugar $y$, donde acontece un hecho $z$. Conociendo los datos biográficos de un autor, extraeremos las verdaderas intenciones por las que escribió el libro, y comprenderemos mejor sus sentimientos, preocupaciones, reivindicaciones, etc. Pero además, el profesional de la lengua debería extrapolarse a la propia enunciación conectando las informaciones de un modo lineal y aplicarlas al proceso ontológico.

\subsection{Muestreo textual a partir de una novela de propia autoría}

A través de un muestreo textual llevado a cabo en la asignatura de Traducción de Textos Alemanes (Grado en Lengua y Literatura Alemanas de la Universidad de Sevilla), ${ }^{6}$ se llevó a cabo la traducción de diversos fragmentos escogidos de una obra de mi propia autoria, "La esquina del pecado". Partiendo de los fragmentos, el alumnado debía extraer conclusiones sobre el significado abstracto del metatexto. ${ }^{7}$

Los resultados fueron enriquecedores en varios sentidos, aunque destacaron sobre todo implicativos políticos y humano-sociales, concluyéndose que la novela es fruto del intento de mejorar el concepto de diversidad en nuestra aldea global. En otras palabras y según afirma Nicholas Birns (2010, p.79) What we do have access to is the novelist's own discourse, superimposed over the various ideological standpoints expressed in the novel as characters. Se constata así que todas mis impresiones como autora eran contadas de la mano de los personajes ficticios que vivieron en la España postransicionista, pero desde un punto de vista que la historia no narraría por ser demasiado subjetivos, y

5 Independientemente de la estructura o guión de inicio de una historia, núcleo o fin.

6 Asignatura obligatoria de $3^{\circ}$. Código 1850056 [Plan de Estudios de 2009].

7 Para ponernos en la situación del ejercicio práctico, podemos afirmar que "La esquina del Pecado" pretende ser una historia marginal, social y pedagógica. Los protagonistas son dos enamorados que con el tiempo se reencuentran, cuando una de las partes lleva una vida considerada normal. Y partiendo de estos datos, ambos se ven envueltos en una serie de acontecimientos que rozan lo surreal: los protagonistas cometen asesinatos y/o los consienten, entienden la vida de una forma peculiar desatendiendo normas y transforman los parámetros de sus propias acciones -asesinatos y encubrimientos- justificándolas. Y todo ello acontece en la España Vacía de finales de los setenta y principios de los 80 , cuando las ideas socialistas comienzan a estar en boga. 
cómo los tabús y los miedos a prejuicios se despliegan dando paso al hilo conductor que termina cambiando la actitud de los personajes normales, que también adoptan actitudes cuestionables desde un principio. Y si bien la recepción de la novela por el alumnado-traductor podía ser interpretada de varios modos, sí coincidieron en que la protagonista es una mujer de mala vida, un hecho inevitable si se quisiera hablar de machismo. Dejamos constancia de algunos fragmentos analizados:

Fragmento 1

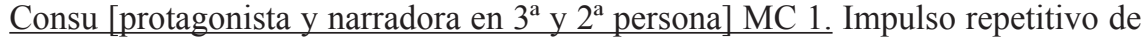
búsqueda de Martha. Elementos: expresión de las emociones, charlas esporádicas, cambios de opinión, luz

-Partiré de aquí - le dije-, aún a riesgo de ser descubierta, porque una vida en sombra es mucho peor que vivir sabiendo que existe la luz afuera.

Me emocioné al pronunciar estas palabras, eran el eco de mi interior, transformándose y en constante movimiento circular. Quería romper la trayectoria.

-Puedes marcharte — me dijo él-. Te comprendo. ${ }^{8}$

Fragmento 2

Herminia [amiga de Consu] MC 2. Recuerdos de la vida de Consu tras la pérdida de memoria. Elementos: fotos, ropa, acompañantes masculinos, acusaciones indirectas

Algo escondía Herminia en su mano. Finalmente me atreví a preguntarle:

- ¿Qué tienes ahí, querida amiga?

-Unas fotos tuyas.

- ¿De dónde y de qué?

- Estaban en la cocina, el caso es que me han llamado mucho la atención. Mira, apareces tú en ropa interior y siempre te acompaña un señor diferente. ¿Era esto a lo que te dedicabas antes? Disculpa si me meto donde no me llaman, pero hay rumores... Se dice... Se comenta que eras prostituta. ${ }^{9}$

Fragmento 3

Andrés [esposo de Consu] MC. 3 Presagio de malos tratos

Elementos: amenazas, arrepentimientos, gritos-silencios

Martha enseguida puso cara de arrepentida, despegándose de mí con disgusto y pesar. Miró hacia el suelo y calló. En cambio, Andrés supo romper el silencio:

- iA casa! - gritó contundente.

-No. Déjame en paz —repliqué.

- Atente a las consecuencias. ${ }^{10}$

Fragmento 4

Martha [amante de Consu] MC. 4 Viaje a Budapest

8 Op. Cit. Ibídem 105.

9 Op. Cit. Carmen Castro, pág. 129.

10 Op. Cit. Ibídem, pág. 157. 
Elementos: distracción, paseo, alimentos, bienestar

[...] Tuve de dejarla con la palabra en la boca y no le pregunté nada porque Martha ya atravesaba el puente que la conducía al otro lado del río, a Pest. Una vez accedió al edificio del mercado reparaba en cada rinconcillo, degustaba productos típicos y olisqueaba salchichones de paprika. Recorrió la planta baja procediendo de ese modo, para luego acceder por unas escalinatas a la alta, en donde se podían adquirir productos textiles.

Fragmento 5

Agustín [mantenido de Consu] MC. 5 Anécdotas de la mala vida

Elementos: alcoholismo, espacios inciertos, desconfianza, fertilidad

Consulté a un amigo de confianza, Agustín, que aunque bebedor las tenía todas consigo, y rápidamente nos pusimos de acuerdo en actuar siguiendo las directivas de las calles expresadas en el escrito.

En su vehículo nos encaminamos a las fincas, que escaparon a las dimensiones esperadas. En hectáreas infinitas se debatieron los campos de la fertilidad hallados. $Y$ una enorme casona abandonada nos encandiló desde el inicio. ${ }^{11}$

\subsection{Conclusiones}

Teniendo en cuenta los datos extraídos de los pasajes de la novela que enlazaban los acontecimientos, el alumnado pudo analizar las Metáforas del Conocimiento y cómo éstas facilitaban la práctica de la traducción mejorando sus ideas previas. Son varias las competencias específicas que se abordaron:

- $\quad$ La comprensión y valoración de la diversidad lingüística y cultural;

- $\quad$ El reconocimiento de los componentes socio-lingüísticos;

- $\quad$ La gestión eficaz de los presupuestos de la comunicación intercultural;

- La atención a la sincronía y diacronía de una tipología textual o discursiva;

- La aplicación de las fuentes y herramientas necesarias.

Podemos entender que analizando las MC el profesional de la traducción mejora sustancialmente la adaptación estilística y cultural en el proceso de transferencia de una lengua a otra. Como consecuencia indirecta transversal se fomentan la capacidad de síntesis y la reflexión crítica que garantiza el respecto a los derechos humanos y a los principios de accesibilidad. La esquina del pecado cuenta con un final feliz de maternidad y plenitud.

\section{La didáctica de la traducción: árabe Rosa-Isabel Martínez Lillo}

\subsection{Introducción}

Hace más de una década la Profesora María Jesús Rubiera Mata nos introducía al tema con las siguientes consideraciones: «Las dificultades del aprendizaje de la lengua árabe

11 Op. Cit. Ibídem, pág. 15. 
para un hispanohablante, sean muchas o pocas, subjetivas u objetivas, no son el tema del que se hablará en estas páginas dedicadas a la traducción del árabe al castellano, ya que el traductor de una lengua extranjera ha tenido que superar ese aprendizaje con crecer y, desde luego, vencer, en un primerísimo momento, la dificultad más subjetiva de todas para un estudiante europeo de lengua árabe, el aprendizaje del alifato, el alfabeto árabe, que como un velo islámico oculta el rostro de la lengua y hace temer al extraño que será imposible llegar a vislumbrar sus facciones. Pero no hay rigurosos parientes impidiendo retirar el velo de las bellas letras árabes y al hacerlo la lengua árabe resulta no ser tan exótica como podría suponerse, por ser una lengua flexionada, es decir con el mismo sistema que las lenguas indoeuropeas». (RUBIERA MATA, 2004, p.19)

Al margen de la bella metáfora, en la línea de la poeticidad de la propia lengua árabe, la profesora ya apuntaba una de las principales coordenadas a tener en cuenta a la hora de la didáctica de la traducción: singularidad y pluralidad, elementos de divergencia y convergencia; puentes entre lenguas, civilizaciones y seres humanos, en definitiva, verdaderos artífices a la hora de plantear el hecho de la traducción y su didáctica.

$\mathrm{Y}$ es que en tal didáctica, además de dar a conocer las constantes vitales propias de cada lengua -ente vivo-, la noción de contraste es básica; intentar que el alumno conozca, pero también compare, entienda, pero también relacione, resultará en piedra angular.

En el caso concreto de nuestra lengua, la citada profesora proseguía: «En muchos sentidos es familiar al hispanohablante que ha utilizado los arabismos en castellano, no desdeñables en número por los préstamos medievales del árabe. Hay arabismos donde incluso pueden distinguirse algunos rasgos morfosintácticos de la lengua originaria como el artículo determinado: el al- de palabras, tanto nombres comunes como propios, como alcázar, almadraba, Alcalá, Alhambra, etcétera.» (Idem, p.19) Lo que claramente puede introducir también, y este caso ya concreto, a realidades históricas: el hecho de que en portugués haya un buen número de arabismos nos porta directamente, entre otras, a la realidad de Alándalus.

Dichos vínculos, lingüísticos, históricos y de cualquier cariz, son los que, además de cuestiones técnicas, enriquecen el hecho de la traducción y su didáctica.

\subsection{Sobre los estudios de Tel (árabe) en España}

Antes de abordar dicho punto resultan necesarias unas palabras, aún someras, sobre la didáctica de la lengua árabe $\mathrm{y}$, de manera general, en los estudios árabes en nuestro país. Heredero, en cierto modo, de la Escuela de Estudios Árabes (1932), será el profesor Emilio García Gómez (1905-1995) quien abra la puerta a dichos estudios de una manera, valga el término, más humana o humanista. Su dedicación a la traducción, eminentemente literaria y centrada tanto en la poesía (andalusí y oriental) como en la prosa, impregnan la didáctica de dicha traducción - todavía sin la nomenclatura en sí- del lirismo inherente a su literatura; didáctica que acompañará al estudio de la lengua en sí y su cultura ${ }^{12}$. Posteriormente los estudios árabes darán un paso primordial hacia la visión de la contemporaneidad gracias al profesor Pedro Martínez Montávez (1933). ${ }^{13}$

12 En estos primeros momentos referente casi exclusivamente a Alándalus, si bien el mundo contemporáneo comienza a atisbarse gracias, entre otras, a las traducciones de obras de Tawfiq Al-Hakim (1898-1987) y, posteriormente, del Nobel Naguib Mahfuz (1911-2006).

13 Fundador del Departamento de Estudios Árabes e Islámicos y Estudios Orientales de la UAM y primer traductor a una lengua europea de los poetas palestinos de resistencia. 


\section{Conexão Letras}

En la didáctica de la traducción árabe-español dicha herencia, derivada de los estudios árabes como de la dimensión principalmente literaria, será un elemento a tener en cuenta.

Con la inserción de los estudios de TeI en el ámbito universitario, tal didáctica se amplía, tanto en métodos como en contenidos: la Traducción Literaria, en general, pasa a un segundo lugar en beneficio de otras traducciones más técnicas, y quizá necesarias o demandadas socialmente, como Servicios Sociales y Jurídica, preferentemente.

Si bien la didáctica en sí de estas materias tendrá que tener en cuenta la LM y sus realidades vitales, ${ }^{14}$ ciertos elementos, además de los anunciados, no podrán obviarse. De entre ellos, y a partir del ejercicio de esta didáctica en el aula, quizá los más relevantes serían:

- El conocimiento de la lengua y la sociedad de partida y las de llegada; conocimiento en tanto que uso y también a reflexión.

- $\quad$ No existe una traducción única, ideal; el traductor plantea un viaje de ida y vuelta hasta llegar a su traducción definitiva, capaz de transformase según tiempos y espacios.

- Además de las herramientas, el traductor aprende con la propia práctica, va haciéndose, formándose.

\subsection{Teoría y práctica: una posible aproximación en el aula}

Siempre a partir de la propia experiencia en el aula, ${ }^{15}$ esta podría plantearse:

\subsubsection{Tipos de traducción:}

$$
\begin{aligned}
& \text { 1ةماعلا ةمجرت (Traducción General) }
\end{aligned}
$$

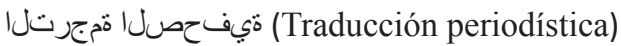

$$
\begin{aligned}
& \text { 2ةتصصنتملا ةمجرتل (Traducción especializada): } \\
& \text { - مينوناقلا ةمجرتل (Traducción jurídica) }
\end{aligned}
$$

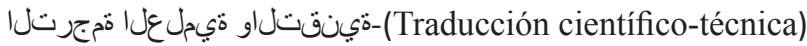

$$
\begin{aligned}
& \text { - ثيداصتقالا تاحلطصجل أمجرت (Traducción económica) } \\
& \text { - ميبدأل ةمجرتل (Traducción literaria)... }
\end{aligned}
$$

Naturalmente la segunda observación consistiría en distinguir entre la traducción de tipo técnico y la literaria, en que el elemento creativo es específico.

\subsubsection{Pasos a la hora de traducir}

Desde la comprensión global hasta la más específica, desde la sintaxis al léxico ${ }^{16}$, siempre haciendo hincapié en que no bastará una ejecución, sino que se necesitarán varias hasta realizar la definitiva.

14 La didáctica varía dependiendo de la geografía donde se realice, pues varía el alumnado.

15 Me centro ahora en mi docencia en la UAM (2002-2017) y las asignaturas de Traducción General 1 y 2.

16 En 1 literaria, y concretamente la poética, el siguiente nivel, el fonético, sería fundamental. 


\subsubsection{Miradas}

Se darán al unísono aquella "horizontal"(visión global de la frase o el texto a traducir) y la "vertical" (cada palabra o, en su caso, casa sonido).

Dependiendo que cada variedad el traductor tendrá que tener en cuenta diferentes factores: en la jurídica, por ejemplo, las variantes regionales de la lengua árabe se hará patente en ciertos vocablos característicos de cada zona, ${ }^{17}$ si bien la estructura gramatical y ciertas fórmulas derivan de la más clásica y literaria lengua árabe. Ello porta, entonces, al conocimiento por parte del traductor no sólo de los diferentes campos vinculados con las traducciones, sino también a las diversas variantes lingüísticas. Desde hace unas décadas se añade otro elemento a tener en cuenta en el ámbito del árabe: el desarrollo o evolución de la lengua a partir de la influencia de los mass-media y concretamente de la prensa; debido a ello, tal vez la forma óptima de enfocar hoy en día la didáctica de la traducción del árabe en el aula podría ser a partir de las noticias periodísticas de diversa índole temática. ${ }^{18}$

\subsection{Conclusiones. A modo de ejemplo: La literatura contemporánea}

Terminemos con un significativo y curioso ejemplo sobre las posibilidades de la traducción, ahora en el creativo marco de la traducción literaria.

En 2003 el novelista egipcio Sun Allah Ibrahim (1938) publica una novela titulada sugerente y significativamente Amrikanli (Amri-kan-li) ${ }^{19}$, título en que apreciamos una deformación del vocablo árabe "Americano"("Amrikani”), dividido en otros tres términos que, en realidad, forman una oración con sentido pleno (Amri kan li="Mi asunto era mío").

Lejos de plantear la imposibilidad de traducción, opino que el docente habrá de abrir puertas a las capacidades creativas del alumnado e incentivarlas. Así, en este caso, las opciones fueron:

\section{1-American-illo}

2-American-iyo

3-EUA (Era Un Asunto sólo mío)

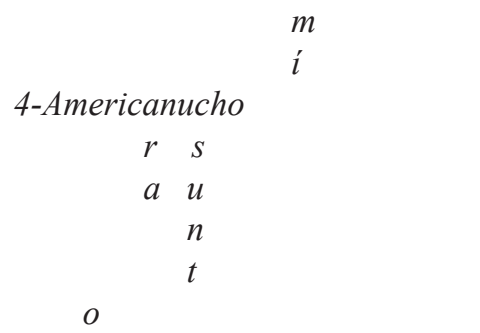

No olvidemos que en la traducción literaria, y como indica el narrador egipcio Ibrahim Aslan (1935-2012): "El traductor. también él, ha de estar inspirado".

17 "Nacimiento", p. e., recibe un nombre en Marruecos y otro en la zona del Mashreq, oriente árabe.

18 Así lo sea ha llevado a cabo este curso 2016-17 en la asignatura de "Traducción General 2", con excelentes resultados.

19 En 2014 Antonio Galán Sánchez, exalumno de la UAM, publica la traducción de su novela Ese olor, Libros de la Ballena. 


\section{La traducción de neologismos al español \\ Violeta de la Jara Berenjeno}

\subsection{Introducción}

'Burkini', 'juernes‘, 'meme' o 'pokeparada' son solo algunos de los neologismos ${ }^{20}$ que están de actualidad y que poco a poco están arraigando en nuestra lengua quizás para lexicalizarse y pasar a formar parte de ella. Nuestra lengua se mantiene en continuo cambio y por ello, los traductores han de adaptarse a los mismos. Abordar la tarea de traducir neologismos no es sencillo; el traductor no solo debe estar bien documentado sino que, en la mayoría de ocasiones, debe decidir si trasladar el término como préstamo o adaptarlo a la lengua mental. Sin lugar a dudas, se deja claro que una de las habilidades de los traductores frente a los neologismos es la creatividad.

En general, se puede afirmar que los neologismos surgen debido a una necesidad de denominar nuevas realidades, conceptos u objetos que aún no han sido nombrados, neología denominativa, o para introducir matices expresivos, neología expresiva ${ }^{21}$. De acuerdo con Guerrero Ramos (1995, p.19), la primera obedece a una necesidad práctica y la segunda a una necesidad expresiva con fines lúdicos o estéticos. De esta forma, tanto por carecer de una unidad léxica análoga en la lengua meta como por introducir nuevos matices, ambos factores deben ser tenidos en cuenta por el traductor.

\subsection{Funciones según tipología}

Sin embargo, la tipología del neologismo no es el único punto a considerar pues la función y/o funciones que presenta dentro de un texto son absolutamente relevantes. Entre las funciones más importantes encontramos:

- Denominar, siendo la función principal, se encarga de llenar los vacíos lingüísticos que se han creado con la aparición de nuevas realidades o nuevas formas de ver el mundo que como se puede comprobar corresponde con la neología denominativa.

- Introducir nuevos matices, que puede presentarse de forma autónoma o ligada a la función anterior para introducir nuevas precisiones, ideas o estilos, que corresponde con la neología expresiva.

- Captar la atención del oyente (apelar). Tal y como apuntan Freixa y Llompart (2013, p.242) la neología estilística se caracteriza por tener una función expresiva y connotativa, ya que intenta mostrar la visión personal del autor y captar la atención del lector; por ello utiliza formas no productivas y poco comunes, porque la finalidad es jugar con las palabras y ser originales, por tanto, son neologismos efímeros. De esta forma, en muchas ocasiones se busca provocar deliberadamente una ambigüedad (mediante bromas o dobles sentidos en los textos) o causar algún efecto poético (enfatizar, causar extrañeza, sorpresa, etc.).

20 En este artículo se usa el término neologismo donde se lo considera como un fait spécifiquement lexical, et lorsque le changement affecte un autre domaine de la grammaire, il n"est jamais analysé en termes de néologie" (1974: 6).

21 Son cuatro los criterios, no excluyentes entre sí, que pueden ser usados para definir a un neologismo según Díaz Hormigo (2008: 9). 


\subsection{Identificación de unidades}

De esta forma, el traductor debe realizar varias tareas en lo que se refiere a la traducción de unidades neológicas siendo la primera la identificación de dicha unidad. Una vez identificada es conveniente que se identifique qué tipo de neologismo es y qué función desempeña en el texto. Sin embargo, aún habiendo determinado la función de la nueva unidad léxica, puede enfrentarse a toda una serie de problemas derivados de ella puesto que se debe recordar que en toda traducción la meta es el concepto y no el término. Según Cabré (2000, p. 2):

El traductor, mediador entre dos interlocutores hablantes de distintas lenguas, ejerce su función poniéndose en la piel del que emite el mensaje y asumiendo sus mismas competencias. Si no lo hace, difícilmente hará una buena traducción. Asumir las competencias de un productor de texto especializado comporta conocer la materia específica, controlar su contenido y manejar la terminología que lo expresa. Y para conseguir que el texto de traducción sea, en relación al original, literal en cuanto a contenido, gramatical en su expresión, adecuado en sus modalidades y ajustado estilísticamente, debe acercarse lo máximo posible a los usos léxicos que habría seleccionado el productor del texto si se hubiera expresado naturalmente en la lengua de la traducción. Debe servirse por tanto de los términos.

Así, uno de los problemas principales son los problemas lingüísticos que se encuentran intrínsicamente ligados a los neologismos y que vienen determinados por las discrepancias de formas entre ambas lenguas. Pudiera parecer que decidir entre préstamo, adaptación o traducción es una tarea relativamente sencilla, y podría serlo si se obvia el componente pragmático de dicha unidad, sin embargo, como se explicaba con anterioridad, muchos neologismos tienen una carga estilística que debe ser mantenida con el fin de ser fiel al texto original, es decir, optar por el préstamo puede significar una pérdida de matices importantes al igual que optar por la adaptación o traducción puede significar la pérdida de rima, onomatopeyas, etc. Añadido a este hecho encontramos que la decisión de un traductor no solo afecta al texto en el sentido antes indicado, también afecta al destinatario pues, de manera indirecta, la decisión del traductor, si su texto goza de la suficiente repercusión, influye en la formación del corpus de la lengua meta.

Por otra parte, y en menor medida, la falta de actualización y/o de tiempo del traductor también supone un problema en la traducción general de un texto y en concreto de la neológica. Este hecho provoca duplicidades, sinonimia, etc. ya que la unidad en cuestión puede haber sido incluida previamente en la lengua meta en forma de préstamo, préstamo adaptado o traducción. Por lo tanto, la documentación se convierte en un requisito indispensable para determinar si la unidad léxica ha sido previamente traducida o no. En este sentido, cuando un traductor se encuentra ante un neologismo, que no ha sido anteriormente traducido, y decide optar por la adaptación la aplicación de los mecanismos de creación neológica, detallados por Cabré (2006, p.232-233), Varo Varo, Díaz Hormigo y Paredes (2009, p. 190191) o Guerrero Ramos (2010, p. 24-41) entre ellos autores, a la traducción de neologismos es altamente recomendable; sin embargo, tal y como asegura Verdegal (2003, p. 8):

no pueden olvidarse las restricciones propias de la idiosincrasia de la lengua término (de orden semántico, sintáctico, morfológico o fónico), ni tampoco otros condicionantes inherentes a cada uno de los métodos de formación de palabras, como las características que deben cumplir los compuestos, la manera de combinar sus elementos, el comportamiento y la clasificación de los derivados, los grupos sintagmáticos y las abreviaciones. 


\subsection{Conclusión}

Por los motivos antes expuestos cabe resaltar que la traducción de la neología ha de ser realizada de manera razonada. Sería pues deseable y esperable que en dicha tarea se valorasen las ventajas y/o problemas que se pueden derivar tanto del mantenimiento del término de la lengua origen en la lengua meta como de la adaptación o traducción del mismo en la lengua meta.

\section{Consideraciones finales}

A partir de la visión de las cuatro autoras se procuraron hacer patentes los diferentes puntos de vista que puede presentar la traducción tratada desde su pragmática didáctica. En cada uno de los idiomas expuestos, el italiano, alemán, árabe y español, fueron explicitados aspectos aplicables a la hora de su docencia, si bien se coincidió en que éstos eran, a su vez, atribuibles de un modo genérico. Se abordaron, entre otras, materias como la progresión de la enseñanza a nivel universitario mediante la especificación de objetivos concretos y dependiendo de las fases; la metodología mediante el diseño de unidades específicas de cada idioma, atendiendo a diversas tipologías textuales; o los procedimientos de (auto)evaluación y sus metaindicadores, así como sus criterios e instrumentos.

\section{Bibliografía y sitografía}

\section{Giuseppa Giangrande}

BALBONI, P.E. Fare educazione linguistica. Insegnare italiano, lingue straniere e lingue classiche, Torino: UTET Università, 2013.

BALBONI, P.E. Le sfide di Babele. Insegnare le lingue nelle società complesse. Torino: UTET Università, 2015.

CARRERES, A. Strange bedfellows: Translation and Language Teaching. The teaching of translation into L2 in modern languages degrees; uses and limitations, 2006. In: www.cttic.org/ACTI/2006/papers/Carreres.pdf puntoeduri.indire.it/ocse/lo/292/files/ relaz_psico_nannoni.doc TITONE, R. Il tradurre. Dalla Psicolinguistica alla Glottodidattica. Roma: Armando, 1998.

\section{Carmen C. Castro Moreno}

CASTRO MORENO, Carmen C. La esquina del pecado. Madrid: Editorial ViveLibro, 2017.

GARCÍA MEDALL, Joaquín. La traducción en la enseñanza de lenguas. Hermeneus: Revista de Traducción e Interpretación, Universidad de Valladolid, n. ${ }^{\circ}$ 3, p. 113-140, 2001. VERMEIREN, Hildegard. Escribir es traducir, traducir es escribir. COPERÍAS, M. J.; REDONDO, J.; SANMARTÍN, J. (eds.) Quaderns de Filologia. Estudis linguistics 5, (Aprendizaje y enseñanza de una segunda lengua), p. 355-370, 2000.

VIQUEIRA, Maria José. Revalidación de la traducción como elemento de trabajo en el inglés científico. En AA.VV.: Actas del II Congreso Luso-español de Línguas Aplicadas às Ciências. Évora: Universidade de Évora y Universidad de Extramadura, 1992. p. 76-78 ZARO, Juan Jesús. La traducción, estrategia y objeto de aprendizaje. In: SALABER- 
RI RAMIRO, M.S. (ed.), Lingüistica aplicada a la enseñanza de lenguas extranjeras. Almería: Universidad de Almería - Servicio de Publicaciones, 1999. p. 531-555

Rosa Isabel Martinez Lillo

DAWD AL-WASITI, S. Taryamat al-nass al-shi 'ri ("La traducción del texto poético"), Wazarat al-thaqafa wa-1-i 'lam, Bagdad, 1986.

EPALZA, M. Traducir del Árabe. Barcelona: Gedisa, 2004.

MARTÍNEZ LILLO, R.-I. La literatura: un medio para el diálogo y la paz. Voces,

Revista de Teología de la Universidad Intercontinental, México, D.F., año 22, n. 42, p. 97-107, 2015.

PENAS, Azucena (coord.) Teoría y práctica de la Traducción. Ed. Síntesis, Año 22, n. 42, 2017.

RUBIERA MATA, María Jesús, "Introducción general a la lengua árabe y a su traducción al castellano", en Traducir del árabe. Barcelona: Gedisa, 2004, p.19

THE TRANSKATOR. St. Jerome Publishing, Manchester, v. 6, n. 2, 2000.

TAFIQ MOHAMED-ESSAWY, A. Historia de la traducción en la cultura arabo-islámica. Siglos VII-XII, I.E.E.I.-Grupo de Investigación El Saber en al-Ándalus, Sevilla, 2001. VÁZQUEZ, Esther, MARTÍNEZ, R.-I.; ORTIZ, Javier Ortiz. Errores en los exámenes de traducción directa (inglés/árabe-español) general especializada. Granada: UGR, 2011.

\section{Violeta de la Jara Berenjeno}

BASTUJI, J. Aspects de la néologie sémantique. In : GUILBERT et al. La néologie lexicale. Langages, n. 36, p. 6-19, 1974.

CABRÉ, M. T. El traductor y la terminología: necesidad y compromiso.Panace@, v. 1, n. 2, p. 2-4, 2000.

. La clasificación de los neologismos: una tarea compleja. Alfa, n. 50, v. 2, 229-

250, 2006.

DÍAZ HORMIGO, M. T. La investigación lingüística de la neología léxica en España.

Estado de la cuestión. LynX. Panorámica de estudios lingüísticos, n. 7. p.5-60, 2008.

FREIXA, J.; LLOMPART, E. La función comunicativa de los neologismos: caracterización a partir de criterios basados en el uso. XII Congreso AELFE, 2013.

GUERRERO RAMOS, G. Neologismos en el español actual. Madrid: Arco Libros, 1995.

GUERRERO RAMOS, G. Neologismos en el español actual. 3.ed. Madrid: Arco Libros, 2010.

VARO VARO, C.; DÍAZ HORMIGO, M. T.; PAREDES, Y. M. Modelos comunicativos y producción e interpretación neológicas. Revista de Investigación Lingüística: Investigaciones en neología. Codificación y creatividad en lenguas romances, n. 12, 185-216, 2009. VERDEGAL, Joan. La traducción de neologismos. Puntoycoma, 83, p. 7-20, 2003.

Recebido em: 12/05/2017 Aceito em: 30/05/2017 